\title{
ERRATA
}

\section{CONDITIONS FOR A SOLITONIC SOLUTION OF THE DOENER-GOLDIN EQUATION OF QUANTUM MECHANICS}

[Mod. Phys. Lett. B, Vol. 12, No. 13 (1998) 519-527]

E. C. CAPARELLI, S. S. MIZRAHI and V. V. DODONOV

On p. 521, Eq. (6) should read

$$
\begin{aligned}
\psi(x, t)= & \psi_{0}[\cosh \mathbf{k} \cdot(\mathbf{x}-\mathbf{v} t)]^{\lambda_{1} /\left(\lambda_{1}+\lambda_{3}+\lambda_{5}\right)} \\
& \times \exp \left\{i \frac{2 \hbar \tilde{D} \lambda_{1} \lambda_{2}}{\lambda_{1}+\lambda_{3}+\lambda_{5}} \ln [\cosh \mathbf{k} \cdot(\mathbf{x}-\mathbf{v} t)]+k^{2} t \frac{\hbar \tilde{D} \lambda_{1}^{2}}{\lambda_{1}+\lambda_{3}+\lambda_{5}}\right\} .
\end{aligned}
$$

On pp. 524-525, Figs. 1 and 2, the legend " $k b=1$ " should be omitted.

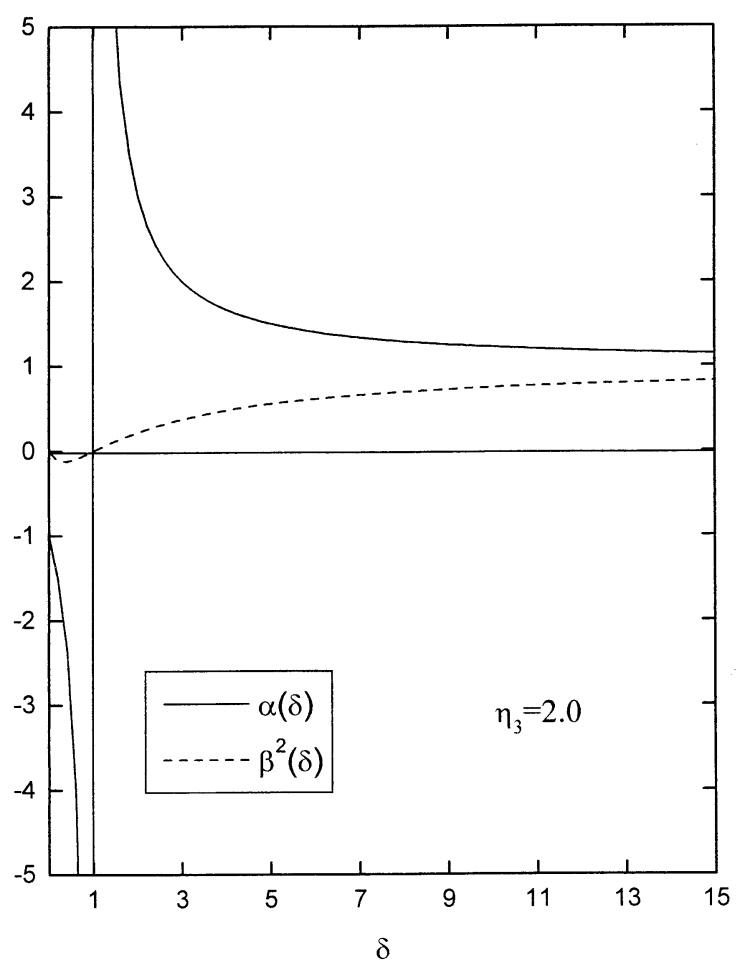

Fig. 1 


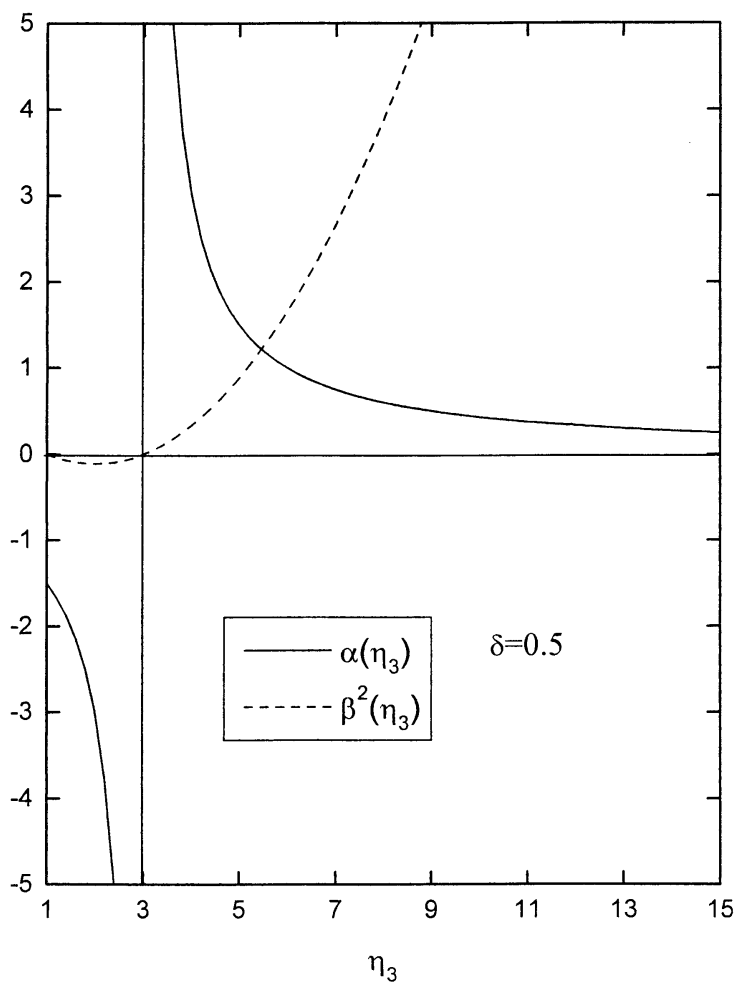

Fig. 2 